\title{
El palacio del Almanzora
}

\section{INTRODUCCIÓN}

El palacio del Almanzora (también denominado palacio de Almanzora, palacio del marqués de la Romana y palacio del marqués de Almanzora) es un monumento del siglo XVIII ubicado en el corazón del valle del río Almanzora que está considerado como el edificio doméstico de estilo neoclásico más espléndido

Se trata de un hermoso edificio de unos seis mil metros cuadrados de suelo sobre una parcela de 2.484, situado en el centro de la aldea de Almanzora, del término municipal de Cantoria, que el Gobierno de España ya había incoado expediente de declaración de monumento histórico artístico el 22 de junio de 1982 y que actualmente está caandaluces por resolución del 2 de febrero de 2006 de la Dirección General de Bienes Culturales.

Pero que a pesar de su hermosura, de su importancia arquitectónica, de su situación estratégica en el de la provincia de Almeria. talogado como patrimonio histórico de todos los

"S.E. recorrió toda la casa, mandó hacer muchas obras de acrecentar la almazara, hacer graneros, cobertizos para secar el maíz, derribar la ermita y hacer otra mayor y más permanente, demarcando al fondo sitios correspondientes para esta obras, pero dejando a fray Pedro de San Agustín y al agrimensor de todo el estado para que, al día siguiente, con mas exactitud, tratasen de los asuntos, delineasen los terrenos y formasen un plan de la obra hecha y de las proyectadas." (DÍAZ LÓPEZ; LENTISCO PUCHE, 2006).

Pronto adquiere este edificio gran protagonismo comarcal, al decidir el X marqués de los Vélez ubicar en él una de las tres administraciones en que dividió sus posesiones en el reino de Granada.

Pasa el palacio a la propiedad de los marqueses de La Romana y en 1872 es adquirido junto con una parte muy importante de las propiedades del marquesado de Los Vélez en la comarca del Almanzora, por D. Antonio Abellán Peñuelas, un rico minero de Cuevas del Almanzora.

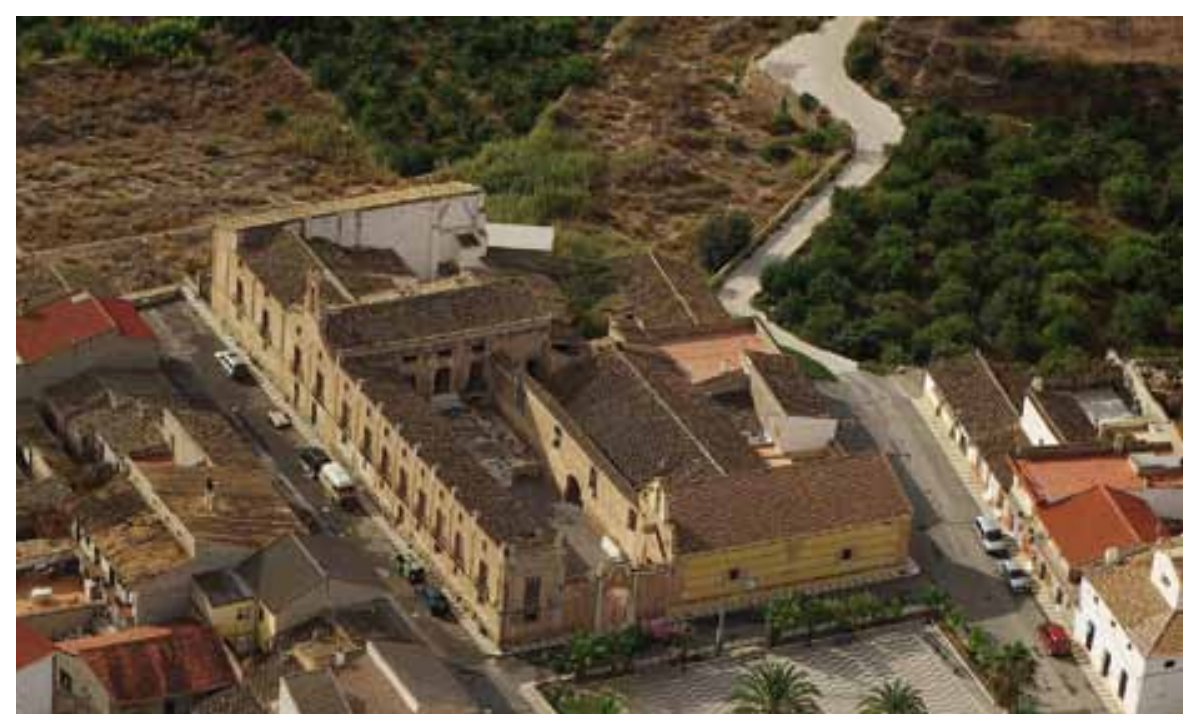

Foto aérea del palacio del Almanzora. Foto: Steve Brockett

corazón del valle del Almanzora y de las disposiciones legales que lo protegen, el palacio se encuentra actualmente en un estado lamentable de abandono que amenaza ruina parcial inminente.

\section{Origen e importancia histórica del palacio}

Recorria Antonio Álvarez de Toledo, X marqués de Los Vélez, sus posesiones en el Reino de Granada, cuando en la tarde del dia 22 de noviembre de 1769 se acercó a Almanzora para conocer la finca que acababa de comprar a la Casa de Benavente. Alli, en el lugar donde antes existió un alcázar árabe que fue uno de los preferidos de los reyes de Granada, habia una casa con bastantes habitaciones, parador, granero, almazara, oficinas y una ermita dedicada a San Ildefonso.
La importancia económica, social y política de Antonio Abellán, que era diputado en las Cortes Generales y que fue premiado por Amadeo de Saboya con el título de I marqués de Almanzora, hicieron que el palacio adquiriese un gran protagonismo comarcal y provincial.

Antonio Abellán, que habia influido decisivamente en la construcción de la línea férrea de Linares a Almeria, fue determinante para que el ferrocarril de Lorca a Baza pasara por el valle del Almanzora y fue en el palacio donde el ingeniero Gustavo Gillman, influenciado por los marqueses, redactó los argumentos justificativos del nuevo trazado, dando solución técnica y económica tanto a la construcción del ferrocarril como a las explotaciones industriales complementarias que lo justificaban (canteras de mármol de Cóbdar, Albanchez y Macael, minas de jaboncillo de Somontín, minas de hierro de Almanzora, Las Menas y Bacares, etc).

La muerte de los marqueses de Almanzora, en 1903 y 1914, y el cierre de las explotaciones mineras de Cuevas del Almanzora, originan la decadencia económica de la familia Abellán que se ve obligada a vender sus posesiones, pasando el palacio a la propiedad de tres familias diferentes, y de ellos a sus herederos.

\section{Descripción arquitectónica del palacio}

El palacio del Almanzora es uno de los escasos ejemplares conservados de vivienda con marcadas pretensiones palaciegas existentes en la provincia de Almeria. Especialmente destacables son sus fachadas y el patio, en los que se puede percibir el abandono de las fórmulas estéticas del barroco a favor de las academicistas.

El inmueble, exento y con una planta general aproximadamente rectangular, consta de un pabellón central y dos alas perpendiculares a aquel, que conforman el Patio de Armas. En el ala de poniente, de estilo barroco y que se corresponde con la obra diseñada por fray Pedro de San Agustín, contiene, además de la capilla, lo que fueron las caballerizas, almazara y dependencias auxiliares. En el pabellón central y en el ala de levante están las dependencias destinadas a viviendas, son de estilo neoclásico y es la zona que transmite el carácter monumental y palaciego a todo el edificio.

El acceso al patio de Armas se efectúa por un vano de medio punto flanqueado por pilastras y coronado por una cornisa mixtilinea bajo la cual se sitúa un escudo heráldico. La rosca y jambas del arco, las pilastras, la cornisa, el escudo y unos jarrones de remate, están realizados en mármol y adheridos a un paramento de cerramiento de ladrillo.

El acceso desde el patio a la vivienda se eleva en dos niveles. Al primer nivel se sube por una escalera de mármol situada en el centro de un muro de ladrillo adornado con pilastras acanaladas de mármol y rematado por una verja. Para alcanzar la puerta de entrada ha de ascenderse aún otra escalera de mármol, en este caso de doble arranque.

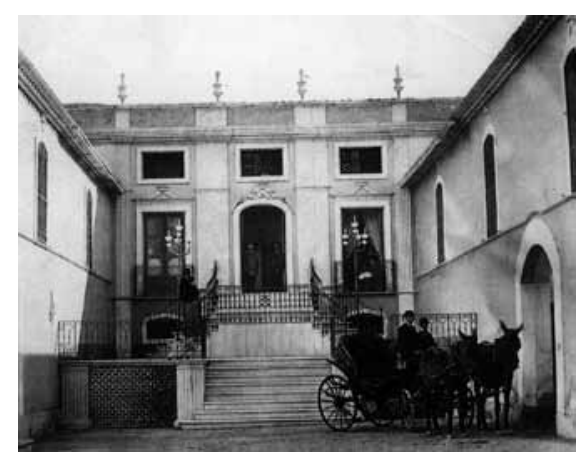

Acceso desde el patio de Armas a la vivienda. Fuente: Fondo Cultural Espín (Lorca). Foto: José Rodrigo 
La fachada donde se encuentra la puerta principal presenta tres plantas. La intermedia, en la que se sitúa la puerta, denota su importancia en el mayor tamaño de los vanos y en su enmarcamiento con adornos de coronas y cuernos de la abundancia. Exteriormente, la fachada de levante presenta muros revocados sobre un zócalo de mampostería. La forma de los vanos varía según las plantas, siendo balcones, rematados por doseles y coronas, en la central. Pilastras acanaladas separan los huecos en las dos plantas superiores. En la fachada sur, con cinco ejes de huecos, se abre un amplio espacio, a modo de atrio, protegido por una verja, por el que se accede a los jardines de palacio.

\section{PROTECCIÓN LEGAL DEL MONUMENTO}

Por Resolución del 22 de junio de 1982 de la Dirección General de Bellas Artes, Archivos y Bibliotecas del Ministerio de Cultura, publicada en el B.O.E. del 6 de octubre de ese año, se incoó el expediente de declaración de monumento histórico-artístico del palacio de Almanzora en Cantoria (Almeria) y el 18 de septiembre de 1995, por resolución de la Dirección General de Bienes Culturales de la Consejería de Cultura (BOJA n. ${ }^{\circ} 3$ de 23 de marzo de 1996) se adecua la protección que gozaba el palacio de Almanzora a lo previsto en la disposición transitoria de la Ley 1/1991 del Patrimonio Histórico Andaluz.

Pero a pesar de la ley, al parecer por un desorbitado retraso en la tramitación de los expedientes, el palacio quedó desprotegido y tuvo que producirse la intervención del Defensor del Pueblo de Andalucía (queja 03/1827) para que el día 2 de febrero de 2006 se aprobara una Resolución de la Dirección General de Bienes Culturales de la Junta de Andalucia, por la que el palacio de los marqueses del Almanzora, en Cantoria (Almeria), se volviese a inscribir, con carácter genérico, en el Catálogo General del Patrimonio Histórico andaluz (BOJA n. 38 de 24 de febrero de 2006).

\section{LA SITUACIÓN ACTUAL DEL PALACIO DEL ALMANZORA}

A pesar de su historia, a pesar de su belleza arquitectónica, a pesar de las recomendaciones del Defensor del Pueblo, a pesar de la protección que goza como patrimonio histórico de todos los andaluces y a pesar de lo importante que podría ser como locomotora que sirviera para impulsar el desarrollo cultural, turistico y empresarial de todo el valle del Almanzora, el palacio lleva más de treinta años deshabitado y, en un $70 \%$ abierto a saqueos y vandalismo, amenazando ruina parcial inminente y siendo un peligro para la integridad física de las personas que lo visitan. Ante esta situación de abandono por parte de los propietarios y de las administraciones públicas, el 14 de noviembre de 2007 nace la Asociación Amigos del palacio del Almanzora, con el objetivo, entre otros, de impulsar su recuperación arquitectónica y su destino a actividades culturales, turisticas y empresariales que beneficien el desarrollo sostenible de la comarca del Almanzora.

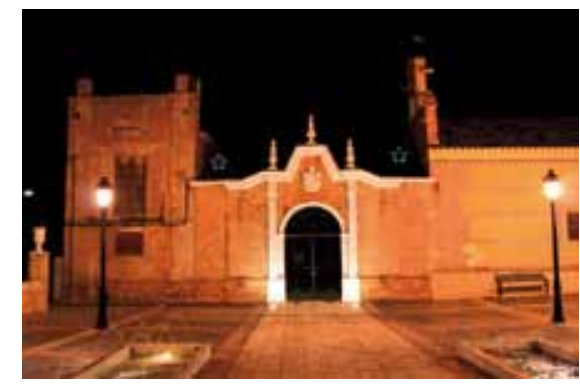

Entrada al palacio desde la plaza. Foto: Diego Piñeiro

Sirva este artículo para divulgar la situación en que actualmente se encuentra el palacio, y como una llamada de atención a las administraciones competentes para que se preocupen por cumplir con las obligaciones que los ciudadanos les hemos encomendado.

\section{Lázaro López Cazorla}

Secretario de la Asociación de Amigos del Palacio del Almanzora

\section{Bibliografía}

DÍAZ LÓPEZ, J. P.; LENTISCO PUCHE, J. D. (2006) $E$ señor en sus estados: diario del viaje de D. Antonio Álvarez de Toledo, X Marqués de los Vélez, a sus posesiones de los reinos de Murcia y Granada 1769-1770. Ayuntamiento de Vélez Rubio, 2006

\section{En la web}

\section{FUNDACIÓN CENTRO TECNOLÓGICO ANDALUZ DE LA PIEDRA \\ www.ctap.es}

Sitio web de esta fundación privada dedicada a la investigación, innovación y desarrollo tecnológico en el conocimiento de la piedra. El sitio ofrece acceso a sus proyectos más importantes así como agenda de eventos, boletín de noticias y espacio multimedia.

\section{VALLE DEL ALMANZORA}

www.valledelalmanzora.org

Plataforma de recursos sobre el valle del Almanzora con información útil de sus municipios: localización, historia, monumentos, fiestas, gastronomía y espacios naturales, entre otros. El portal presenta un amplio elenco de rutas por el valle como la ruta de la minería o la ruta del mármol.

\section{DIPUTACIÓN DE ALMERÍA www.dipalme.org}

El sitio web de esta institución pública ofrece información de interés sobre los municipios que conforman el valle del Almanzora.

\section{GRUPO DE DESARROLLO RURAL LEVANTE ALMERIENSE} www.levantealmeriense.org/gdr

Asociación para el desarrollo de la comarca del levante almeriense a través de la gestión de fondos europeos. Junto a una completa información de los municipios de la comarca, la web ofrece el S.I.G.L.A, Sistema de Información Geográfica del Levante Almeriense, una base de datos cartográfica desarrollada por el grupo local. Publicaciones, proyectos, equipamientos culturales, imágenes son otros de los recursos de este completo y bien estructurado sitio.

\section{INSTITUTO GEOLÓGICO Y MINERO DE ESPAÑA \\ www.igme.es}

Sitio web de este organismo público de investigación adscrito al Ministerio de Ciencia e Innovación. Entre la exhaustiva información que presenta destacan algunos productos como bases de datos, Tesauro de Ciencia de la Tierra, Panorama Minero (archivo histórico sobre sustancias mineras) y una zona didáctica dedicada a divulgar el conocimiento geológico minero entre el público más joven.
INSTITUTO DE ESTUDIOS ALMERIENSES

www.iealmerienses.es

Organismo autónomo de la Diputación de Almería dedicado a la organización y desarrollo de recursos para un mayor conocimiento del panorama almeriense. Promueve una convocatoria de subvenciones de carácter anual para divulgar la cultura almeriense, apoyando las revistas de ámbito comarcal, local y provincial. Contiene un fondo bibliográfico de temática almeriense que cuenta con más de 500 títulos, disponible a través de su biblioteca virtual.

\section{CONGRESO MEMORIAL LUIS SIRET www.memorialsiret.es}

Web del congreso celebrado en el 2010, dedicado a la tutela del patrimonio prehistórico. El sitio permite la descarga de las 37 ponencias sobre este importante evento para el conocimiento de la arqueología andaluza. Entre ellas se encuentra la ponencia "La documentación histórica-arqueológica de la colección Siret sobre la necrópolis de Villaricos (Almeria)".

\section{PATRIMONIO Y TURISMO INDUSTRIAL EN ANDALUCÍA ORIENTAL}

\section{www patrimonioandaluz.con}

Esta web pretende crear un catálogo on line de los principales elementos de patrimonio industrial de las provincias de Almería, Granada y Jaén, para contribuir a la divulgación de sus valores arquitectónicos, culturales y etnográficos. Además de aportar datos históricos, se incluye información sobre hitos cercanos de interés (patrimonio artístico, gastronomía, espacios naturales protegidos...). De forma novedosa, se incluye una sección que recoge la localización exacta de los elementos en forma de POls (Puntos de Interés en formato GPS). 